\title{
Clinical, hormonal and molecular characterization of pituitary ACTH adenomas without (silent corticotroph adenomas) and with Cushing's disease
}

\author{
Gérald Raverot $^{1,2,3}$, Anne Wierinckx ${ }^{1,2,4}$, Emmanuel Jouanneau ${ }^{1,2,5}$, Carole Auger ${ }^{1,2}$, Françoise Borson-Chazot ${ }^{2,3}$, \\ Joël Lachuer ${ }^{1,2,4}$, Michel Pugeat ${ }^{2,3}$ and Jacqueline Trouillas ${ }^{1,2,6}$ \\ ${ }^{1}$ INSERM, U842, Lyon F-69372, France, ${ }^{2}$ Faculté de Médecine Lyon- Est, Université de Lyon, Lyon1, Lyon F-69372, France, ${ }^{3}$ Fédération \\ d'Endocrinologie du Pole Est, Groupement Hospitalier Est, Hospices Civils de Lyon, 59 Boulevard Pinel, F-69677 Bron Cedex, France, ${ }^{4}$ ProfileXpert, Bron \\ F-69500, France, ${ }^{5}$ Service de Neurochirurgie, Groupement Hospitalier Est, Hospices Civils de Lyon, Bron F-69677, France and ${ }^{6}$ Centre de Pathologie Est, \\ Hospices Civils de Lyon, Lyon, Bron F-69677, France
}

(Correspondence should be addressed to G Raverot at Fédération d’Endocrinologie du Pole Est, Groupement Hospitalier Est, Hospices Civils de Lyon; Email: gerald.raverot@chu-lyon.fr)

\begin{abstract}
Objective: Silent corticotroph adenomas (SCAs) are rare pituitary tumours immunoreactive for ACTH, but without clinical evidence of Cushing's disease. We characterized SCAs based on clinical, hormonal and molecular data, and compared the characteristics of these tumours with those of macro (MCA)and micro (mCA)-ACTH adenomas with Cushing's disease.

Methods: Fifty ACTH adenomas (14 SCAs, 15 MCAs and 21 mCAs) with complete corresponding clinical, radiological and biochemical data were selected. Histological corticotroph differentiation; immunostaining for ACTH, $\beta$-endorphin and $\beta$-LPH; and mRNA expression levels of TPIT, POMC, GR $\alpha$, prohormone convertase 1/3 (PC1/3) and galectin-3 were compared in 21 representative tumours. Results: Despite the absence of clinical hypercortisolism in patients with SCA, elevated plasma ACTH levels that were similar to those associated with mCA were observed. The cortisol/ACTH ratio was similar between SCA and MCA groups and lower than that found with mCA $(P<0.05)$. This dissociation could be explained by lower expression of $P C 1 / 3$ in SCA and MCA than in $\mathrm{mCA}(P<0.05)$. After an i.v. dexamethasone suppression test, ACTH levels were significantly higher in patients with MCA than in those with mCA $(P<0.05)$. Cytological and immunocytochemical analyses as well as mRNA expression levels of TPIT, POMC and GR $\alpha$ confirmed corticotroph differentiation in both mCAs and MCAs and in half of the SCAs, with a strong correlation between TPIT and POMC mRNA expression levels in SCAs $\left(R^{2}=0.72 ; P<0.01\right)$ and in MCAs $\left(R^{2}=0.65 ; P<0.05\right)$.

Conclusions: Despite the absence of hypercortisolism, SCAs exhibit histological, biochemical and molecular corticotroph differentiation. SCA and MCA show hormonal and molecular similarities differentiating them from mCA.
\end{abstract}

European Journal of Endocrinology 163 35-43

\section{Introduction}

Corticotroph adenomas, also known as ACTH pituitary adenomas (1), are usually responsible for the occurrence of Cushing's syndrome characterized by clinical manifestations induced by hypercortisolism such as central obesity, moon face, diabetes, hypertension and osteoporosis. In the majority of cases (80\%) (2), pituitary magnetic resonance imaging (MRI) reveals a microadenoma; yet, macroadenomas, commonly associated with symptoms related to tumour mass, can be found. By contrast, silent ACTH adenomas, also named silent corticotroph adenomas (SCAs), are defined as pituitary tumours without clinical evidence of Cushing's disease $(3,4)$. Because of the lack of clinical hypercortisolism together with the presence of symptoms related to tumour mass, biological data are often limited. However, when available, a mild elevation in ACTH levels together with normal cortisol levels has been reported (5-8). More specifically, in some cases, basal plasma ACTH levels were shown to be elevated due to the secretion of high-molecular weight ACTH with no apparent biological activity (9). As such, the incomplete or aberrant processing of proopiomelanocortin (POMC), the large precursor of ACTH, has been suggested to explain the clinical 'silence' of these adenomas. Recently, Tateno et al. (7), showed a downregulation of $P O M C$ and $P C 1 / 3$ genes in SCAs versus corticotroph adenomas with Cushing's disease. However, in this study, micro (mCA)- and macro 
(MCA)-ACTH adenomas were analyzed together, and few clinical data were available. The precise mechanisms behind the clinical 'silence' therefore remain unclear.

In this study, we have analyzed and distinguished the clinical, hormonal and molecular characteristics of SCAs and ACTH adenomas with Cushing's disease, differentiating between MCA and mCA. From our results and the data reported in the literature, we define SCAs and report on their cytopathological, clinical and molecular similarities with MCAs.

\section{Patients and methods}

\section{Patients and assessments}

From our pathological registry of 306 cases of ACTH adenomas operated on at the Hospices Civils de Lyon between 1978 and 2007, we selected 50 patients for whom we had complete clinical, radiological and biochemical data; molecular data were available for 21 tumours for which we had frozen samples.

Clinical presentation as well as pre- and postoperative endocrine status was reviewed for all 50 cases. Preoperative MRI was available for all patients. Tumour size was defined as the largest diameter observed on MRI, and tumour extension and cavernous sinus (CS) invasion were defined according to the Cottier et al. classification (10).

The diagnosis of Cushing's disease was made based on the signs and symptoms of hypercortisolism, increased ACTH plasma levels and serum and urinary cortisol concentrations, a lack of cortisol diurnal rhythm, escape from cortisol and ACTH suppression on i.v. dexamethasone test (according to (11)), and the presence of a pituitary tumour on MRI. The diagnosis of SCA was based on the lack of clinical symptoms of hypercortisolism at presentation and the finding of tumoural ACTH immunoreactivity. According to the inclusion criteria, 36 tumours were associated with Cushing's disease (21 mCAs and $15 \mathrm{MCAs}$ ), and 14 tumours were classified as SCAs. MCA and mCA were analyzed separately. Clinical findings at presentation are summarized in Table 1.

Clinical, biochemical and pathological data from the 21 patients for whom frozen tumour samples were available are detailed in Table 2, allowing a comparison with data obtained from molecular analysis.

Informed consent was obtained from each patient before surgery, and the study was approved by our local ethics committee.

\section{Hormone measurements}

Plasma ACTH was measured by immunoradiometric assay using two MABs for human ACTH (1-39) (Brahms ACTH, Berlin, Germany). The detection limit of the assay is $2.5 \mathrm{ng} / \mathrm{l}$, and the normal range of morning ACTH is $14-26 \mathrm{ng} / \mathrm{l}$.

Plasma cortisol was measured by a specific in-house RIA (12). The normal range of morning cortisol is $352-501 \mathrm{nmol} / \mathrm{l}$. Urinary cortisol was measured by a specific in-house RIA (13) following extraction with dichloromethane. The normal range for men is $10-105 \mathrm{nmol} / 24 \mathrm{~h}$, and for women, it is $15-145$ $\mathrm{nmol} / 24 \mathrm{~h}$.

An i.v. dexamethasone suppression test was performed as described previously (11). Dexamethasone $(4 \mathrm{mg})$ was infused intravenously on day 1 between 1100 and $1500 \mathrm{~h}$. Cortisol and ACTH plasma levels were measured at $0800 \mathrm{~h}$ on day 1 and then at 1100 , 1500,2000 and $1200 \mathrm{~h}$, and finally at $0800 \mathrm{~h}$ on day 2. Morning cortisol and ACTH levels on day 1 and 2 and nadir of cortisol and ACTH levels during the test were taken into account for statistical analysis.

Table 1 Clinical and biochemical characteristics of the 50 patients with ACTH tumours.

\begin{tabular}{|c|c|c|c|c|c|c|}
\hline & $\begin{array}{l}\text { SCA } \\
\text { (mean } \pm \text { S.D.) }\end{array}$ & $\begin{array}{l}\text { MCA } \\
(\text { mean } \pm \text { s.D. })\end{array}$ & $\begin{array}{l}\text { mCA } \\
(\text { mean } \pm \text { s.D. })\end{array}$ & $\begin{array}{l}\text { SCA versus } \\
\text { MCA }\end{array}$ & $\begin{array}{l}\text { SCA versus } \\
\text { mCA }\end{array}$ & $\begin{array}{l}\text { MCA versus } \\
\text { mCA }\end{array}$ \\
\hline Number of patients & 14 & 15 & 21 & & & \\
\hline Clinical signs of hypercortisolism & 0 & 12 & 21 & & & \\
\hline Age (years) & $51.6 \pm 13.7$ & $47.8 \pm 15.6$ & $35.9 \pm 14.7$ & NS & $P<0.05$ & NS \\
\hline Sex ratio $(F / M)$ & $5 / 9$ & $10 / 5$ & $20 / 1$ & NS & $P<0.001$ & $P<0.05$ \\
\hline Tumour diameter (mm) & $27.9 \pm 11.9$ & $20.5 \pm 8.2$ & $5.9 \pm 2.2$ & NS & $P<0.001$ & $P<0.001$ \\
\hline 0800 h ACTH (ng/l) & $118.7 \pm 226.3$ & $162.3 \pm 108.5$ & $58.0 \pm 27.9$ & NS & NS & $P<0.001$ \\
\hline 0800 h cortisol (nmol/l) & $342.9 \pm 112.2$ & $790.0 \pm 343.1$ & $652 . \overline{8} \pm 172.1$ & $P<0.001$ & $P<0.001$ & NS \\
\hline Cortisol/ACTH ratio & $6.8 \pm 4.5$ & $6.9 \pm 4.3$ & $13.5 \pm \overline{7} .4$ & NS & $P<0.01$ & $P<0.01$ \\
\hline 24-h free urinary cortisol & $\mathrm{ND}^{-}$ & $144 \overline{0} .7 \pm 1903.3$ & $735 . \overline{4} \pm 935.9$ & NA & NA & NS \\
\hline 0800 h post-DXM ACTH (ng/l) & ND & $202.4 \pm 272.3$ & $58.6 \pm 31.6$ & NA & NA & $P<0.05$ \\
\hline Nadir DXM ACTH (ng/l) & ND & $90.2 \pm 129.4$ & $20.6 \pm 22.7$ & NA & NA & $P<0.05$ \\
\hline $0800 \mathrm{~h}$ post-DXM cortisol (nmol/l) & ND & $731.6 \pm 407.5$ & $555.9 \pm 252.5$ & NA & NA & NS \\
\hline Nadir DXM cortisol (nmol/l) & ND & $321.0 \pm 278.4$ & $211.8 \pm 194.4$ & NA & NA & NS \\
\hline
\end{tabular}

SCA, silent corticotroph adenoma; MCA, macro-ACTH adenoma; mCA, micro-ACTH adenoma; DXM, i.v. infusion dexamethasone suppression test; NA, not applicable; ND, not done; NS, not significant. 


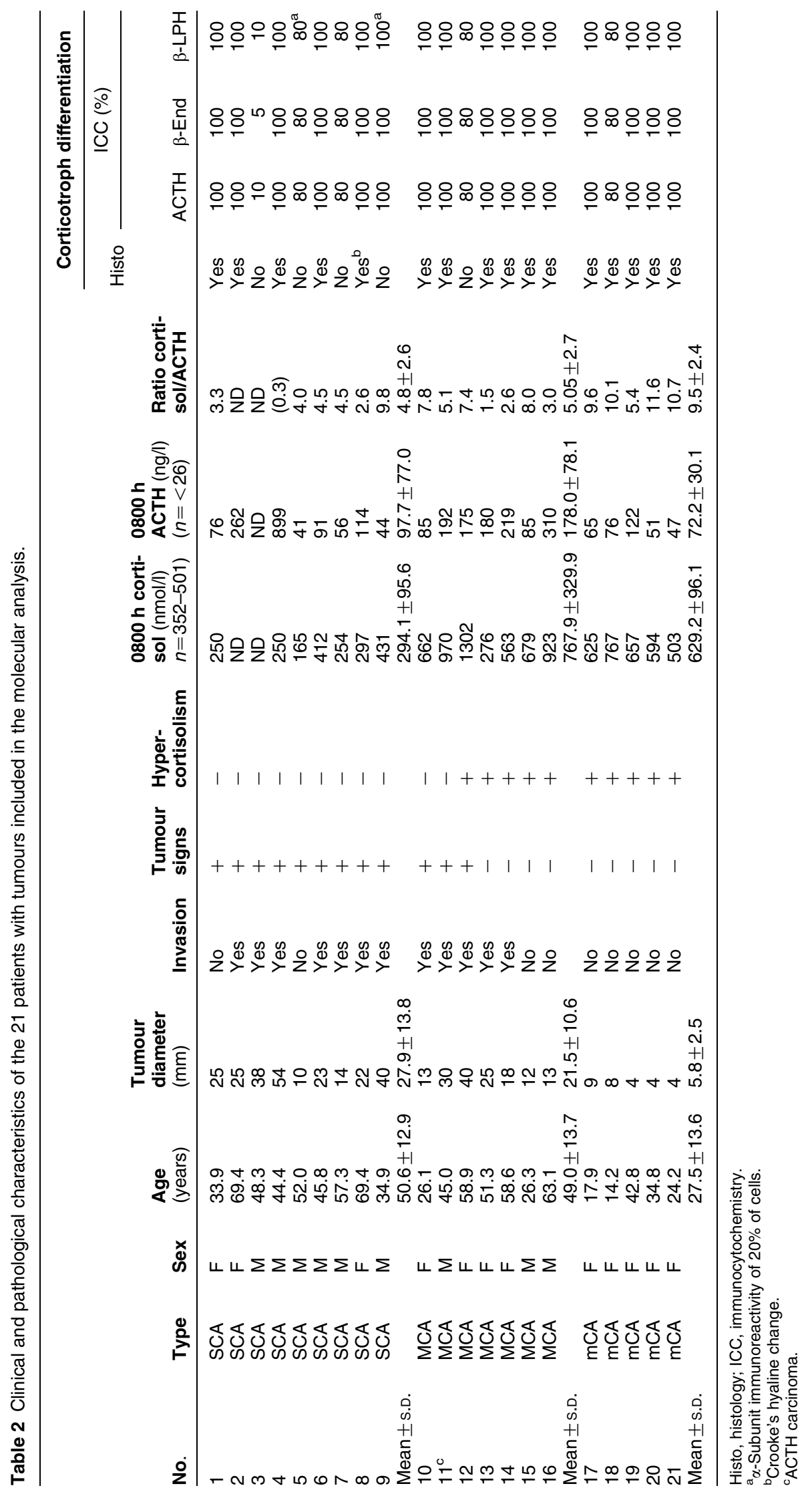




\section{Pathological methods}

For each tumour, fragments were fixed in Bouin's fixative and embedded in paraffin for routine analysis by hematoxylin-eosin and Herlant's tetrachrome staining, periodic acid-Schiff (PAS) reaction and immunocytochemistry. Other fragments were frozen immediately and stored at $-80^{\circ} \mathrm{C}$ (Neurobiotec Bank, Lyon, France). Pituitary hormone detection was performed using the indirect immunoperoxidase method. The following monoclonal $(\mathrm{m})$ or polyclonal $(\mathrm{p})$ antibodies were used: anti-17-39 $\mathrm{ACTH}_{\mathrm{p}}(1 / 20000$, a gift from $\mathrm{M}$ $\mathrm{P}$ Dubois), anti- $\beta$-endorphin $\mathrm{p}(1 / 500$, a gift from $\mathrm{B}$ Claustrat, Lyon, France), $\beta$-LPHp $(1 / 5000$, a gift from MP Dubois), anti-cytokeratin $\mathrm{m}_{\mathrm{m}}(1 / 200$, Immunotech, Marseille, France), anti- $\alpha$-SUm (1/400, Immunotech), anti-prolactin $_{\mathrm{m}}$ (1/400, Immunotech), anti-GHp (1/15 000, National Institute of Health, Bethesda, MD, USA), anti-Ki-67 (Mib1, 1/50, Dako, Glostrup, Denmark) and anti-p53 (clone DO-7, 1/200, Novocastra Laboratories, Newcastle upon Tyne, UK). An initial manual immunostaining using the ACTH, Ki-67 and p53 antibodies was performed at diagnosis, and a second one was done automatically with the same antibodies at the same time for all the tumours using the Benchmark XT, Ventana Medical Systems, Tucson, AZ, USA. To determine Ki-67, p53 and mitotic indexes, we counted cells for ten representative fields per tumour at $400 \times$ magnification, with an average count of 5000 nuclei. Ki-67 and p53 labelling was expressed as a maximum percentage, and the mitoses were expressed by their absolute number.

For all 50 tumours, the diagnosis of ACTH adenoma was based on the immunostaining with anti-ACTH antibody. By histology, corticotroph differentiation was considered as evident (yes), when the tumour exhibited typical signs of ACTH adenoma, i.e. the tumour consisted of monomorphic round cells arranged diffusely with a sinusoidal pattern around the capillaries. The cells were basophilic and PAS positive, and showed strong immunostaining with anti-cytokeratin ${ }_{m}$ antibody. Corticotroph differentiation was considered as non-detectable by histology (no) when tumour cells were chromophobic and PAS negative, and showed only weak immunostaining with anti-cytokeratin $\mathrm{m}_{\mathrm{m}}$ antibody. The corticotroph differentiation and the immunostaining of the 21 tumours with the corresponding molecular data are detailed in Table 2.

\section{Molecular analysis}

Genetic analysis was performed on the fragments obtained from the 21 frozen tumours. We used q-RT-PCR to detect the expression of the following five genes: POMC, TPIT, GR $\alpha$, prohormone convertase 1/3 (PC1/3) and galectin-3.

Total RNA was extracted using an RNeasy minikit (Qiagen), and treated with DNAse according to the manufacturer's protocol. Total RNA yield was measured by OD260, with an A260/A280 ratio of 1.9-2.1 indicating a high level of purity. The quality was evaluated on nanochips using the Agilent 2100 Bioanalyzer (Agilent Technologies, Palo Alto, CA, USA).

Total RNA $(0.5 \mu \mathrm{g})$ was reverse transcribed using MMLV reverse transcriptase (Invitrogen). The cDNA that was synthesized was measured using q-RT-PCR (SYBR Green PCR, LightCycler, Roche Diagnostics) according to the manufacturer's recommendations. The LightCycler experimental run protocol consisted of an initial Taq activation at $95^{\circ} \mathrm{C}$ for $10 \mathrm{~min}$ followed by 45 cycles of the amplification and quantification program $\left(95^{\circ} \mathrm{C}\right.$ for $15 \mathrm{~s}, 60{ }^{\circ} \mathrm{C}$ for $5 \mathrm{~s}$ and $72{ }^{\circ} \mathrm{C}$ for $10 \mathrm{~s}$, with a single fluorescence measurement). The specificity of each PCR amplification was always analyzed with a melting curve program $\left(69-95^{\circ} \mathrm{C}\right)$, with a heating rate of $0.1{ }^{\circ} \mathrm{C}$ per second and continuous fluorescence measurement. Primers were designed with Primer3 software (Whitehead Institute/MIT, USA), and purchased from Eurogentec (Seraing, Belgium). All primers had $T_{\mathrm{m}} \mathrm{s}$ between 59 and $61{ }^{\circ} \mathrm{C}$, and all products were 100-150 bp in length. The internal standard used to control amplification variations due to differences in the starting mRNA concentration was RPL4 mRNA. The relative mRNA levels for each tissue were computed from the $C_{\mathrm{t}}$ values obtained for the gene of interest, the efficiency of the primer set and RPL4 mRNA levels using RealQuant software (Roche).

\section{Statistical analysis}

StatView 5.0 software (SAS Institute Inc., Carry, NC, USA) was employed to perform statistical analysis. Data were expressed as means \pm s.E.M. Differences between groups were examined for statistical significance using Student's $t$-test. $P$ values $<0.05$ were considered statistically significant.

\section{Results}

\section{Initial manifestations}

The 14 patients making up the SCA group (9 males and 5 females; mean age: $51.6 \pm 13.7$ years) were diagnosed because of pituitary tumoural symptoms: visual field defect $(n=7)$, headaches $(n=4)$ and amenorrhoea/ galactorrhoea $(n=3)$, tumour apoplexy with extraocular paresis, or rhinorrhoea $(n=1)$. High blood pressure and obesity were present in three patients within the SCA group, but with an incidence similar to that observed in the general population of the same age and with no other signs suggestive of hypercortisolism (Table 1).

For 15 patients of the MCA group ( 5 males and 10 females; mean age: $47.8 \pm 15.6$ years), the clinical presentation was heterogeneous with 3 patients 
showing symptoms related to the tumour mass effect and 12 patients presenting typical signs of hypercortisolism that were associated with symptoms related to the tumour mass effect in 2 cases.

The 21 patients with mCA (1 male and 20 females; mean age: $35.9 \pm 14.7$ years) had clear clinical symptoms of hypercortisolism with weight gain $(n=19)$, high blood pressure $(n=7)$, depression $(n=4)$, diabetes $(n=7)$, purplish skin striae $(n=10)$, hirsutism $(n=8)$ and amenorrhoea $(n=12)$. These patients were younger than those within the SCA $(P<0.05)$ group. The sex ratio also differed in the mCA group, with only one male, when compared with that of the SCA and MCA groups $(P<0.001$ and $P<0.05$ respectively), within which there were as many or more males than females. The main data are presented in Table 1.

\section{Preoperative hormonal data}

Preoperative $0800 \mathrm{~h}$ serum cortisol and ACTH concentrations were available for 12 of the 14 SCA patients and for all patients within the MCA and mCA groups (Table 1). Serum cortisol concentration was normal in all patients within the SCA group. However, despite the lack of signs of clinical and biological hypercortisolism, ACTH concentrations were elevated in all patients within the SCA group for whom data were available (mean: $118.7 \pm 226.3 \mathrm{ng} / \mathrm{l}$ ). Moreover, one patient (patient no. 4 in Table 2) presented with strongly elevated ACTH levels associated with low cortisol levels. Because of the severity of the symptoms related to the tumour mass effect together with the absence of signs of hypercortisolism, SCA patients did not undergo a screening test for Cushing's disease. The two patients with incomplete preoperative biochemical data were classified as having SCA because of the data obtained at follow-up. Indeed, one patient presented with a significant postoperative residual tumour with elevated ACTH (52 ng/l) and normal cortisol (302 nmol/l) levels, and the tumour of the other patient recurred 3 years later without clinical hypercortisolism associated with elevated ACTH levels ( $41 \mathrm{ng} / \mathrm{l})$ yet normal cortisol levels $(393 \mathrm{nmol} / \mathrm{l})$.

Patients within the MCA and mCA groups had elevated $0800 \mathrm{~h}$ serum cortisol (mean: 802.2 $\pm 790.0 \pm 343.1$ and $652.8 \pm 172.1 \mathrm{nmol} / \mathrm{l}$ respectively) and ACTH (mean: $162.3 \pm 108.5$ and $58.0 \pm 27.9 \mathrm{ng} / \mathrm{l}$ ) concentrations. Morning cortisol levels were significantly lower in patients within the SCA group than in those within the mCA $(P<0.001)$ and MCA $(P<0.01)$ groups, with the latter groups showing no difference between them. Morning ACTH levels were significantly lower in the mCA group than in the MCA group $(P<0.05)$, and were higher, though not significantly, in the MCA group than in the SCA group. This observed dissociation between levels of cortisol and ACTH could be assessed by calculating the
cortisol/ACTH ratio. This cortisol/ACTH ratio was significantly higher in patients in the $\mathrm{mCA}$ group than in those in the SCA and MCA groups $(P<0.01)$ among whom no difference was found (Table 1 ).

ACTH and cortisol suppression after the i.v. dexamethasone test and 24-h free urinary cortisol levels were available for all but one patient from the mCA group and only in patients with signs of hypercortisolism at presentation within the MCA group $(n=12)$. Free urinary cortisol levels were higher, though not significantly, in the MCA group than in the mCA group. Nadir cortisol levels during the i.v. dexamethasone test or cortisol levels after suppression showed no difference between MCA and mCA groups. However, nadir ACTH levels during the i.v. dexamethasone test and ACTH levels after it, were significantly higher in the MCA group $(P<0.05)$ than in the mCA group (Table 1).

The 21 tumours with clinical, biochemical, histological and molecular data were representative of the three subgroups of tumours (SCA, MCA and mCA) with similar presentation (sex ratio, age, tumour size, percentage of tumour invasion, cortisol and ACTH secretion, and cortisol/ACTH ratio; Table 2).

\section{Pathological and molecular data}

All SCAs were found to be macroadenomas with no apparent difference in size compared with MCAs (Table 2). Invasion was noted in $77.7 \%$ of the cases within the SCA group and in $71.4 \%$ of the cases within the MCA group. CS invasion and sphenoid sinus (SS) invasion were respectively present in 55.5 and $22.2 \%$ of the cases in the SCA group, and in 57.1 and $42.8 \%$ of the cases in the MCA group. None of the selected five microadenomas associated with Cushing's disease presented sphenoid sinus or CS invasion.

As shown in Table 2, all five mCAs harboured a histological and immunocytochemical corticotroph differentiation. Six of seven patients with MCA and five of nine patients with SCA exhibited typical ACTH tumours, one of which was a Crooke's cell subtype (no. 8). Five tumours could not be recognized as ACTH adenomas by histology, and the diagnosis was made based on the systematic immunocytochemical detection of POMC peptides. Except for one tumour (no. 3), all or a majority of cells were positive for the three antibodies against POMC peptides. In two tumours (nos 5 and 9), a focal immunoreactivity for glycoprotein $\alpha$-subunit was also present. A pituitary apoplexy was observed in one tumour (no. 14). Concerning the proliferative markers, no difference was observed between the three groups. The mitoses were few, except in two patients with mCA. The Ki-67 labelling index was below 3\%, even in the carcinoma (no. 11). P53 immunodetection and nuclear atypia were infrequent and observed in all three groups. 


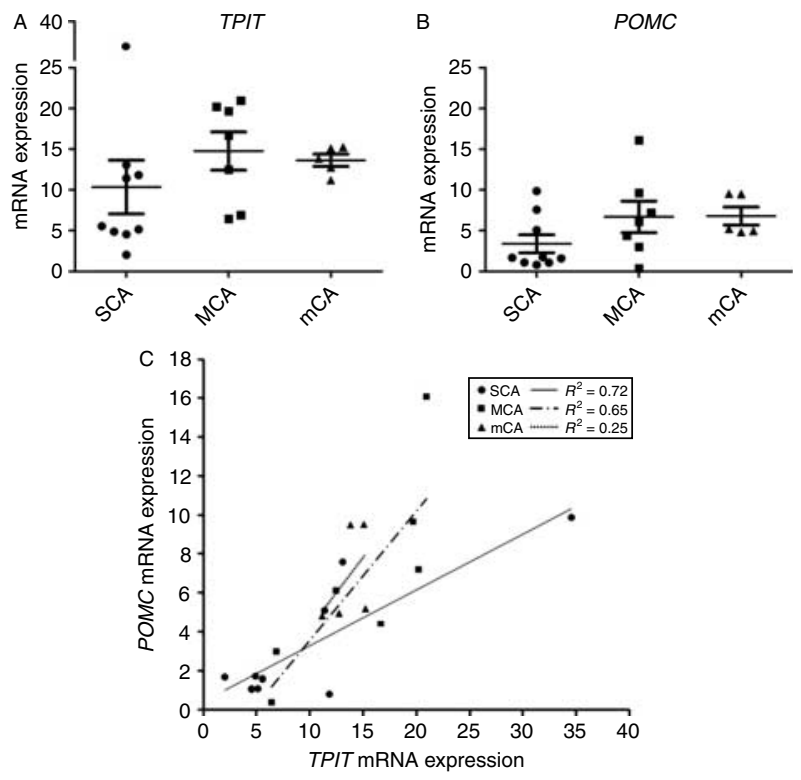

Figure 1 Relative mRNA expression of TPIT (A) and POMC (B) in the three groups of ACTH tumours and correlation between TPIT and POMC (C) mRNA expression levels in each group. Gene expression in normal pituitary tissue was used as a standard and set to 1. RPL4 was used as an internal standard. Bars represent the median.

Expression profile of genes associated with corticotroph differentiation $P O M C$ expression was found in every tumour sample with no expression of any of the other hormone-encoding genes, thus excluding any tissue contamination with normal pituitary. Moreover, TPIT and GR $\alpha$ expression confirmed the corticotroph differentiation in these tumours (Figs 1 and 2).

The level of mRNA expression of POMC and TPIT in the mCA group was homogeneous, and showed no difference in the overall expression levels found in the two other groups (SCA and MCA). In contrast, expression levels of $P O M C$ and TPIT varied greatly within the SCA and MCA groups (Fig. 1A and B). Interestingly, a significant correlation was found between levels of TPIT and POMC mRNA expression both in SCA $(P<0.01$, $\left.R^{2}=0.72\right)$ and in MCA $\left(P<0.05, R^{2}=0.65\right)$ (Fig. 1C), which persisted whether macrocorticotroph adenomas were analyzed alone or together with SCA (MCA + SCA, $\left.P<0.001 ; R^{2}=0.60\right)$. No correlation was noted in the mCA group; however, the number of tumours may not be enough to draw any conclusion.
Expression profile of genes associated with SCA phenotype We analyzed the mRNA expression of GR $\alpha$, $P C 1 / 3$ and galectin-3. No difference was found between the groups in the level of $G R \alpha$ mRNA expression. Levels of $P C 1 / 3$ and galectin-3 mRNA expression varied greatly in the $\mathrm{mCA}$ group, but were consistently higher than that found in all the tumours of the SCA and MCA groups $(P<0.05$; Fig. 2$)$.

\section{Discussion}

A clinical description of SCA remains a challenge since this type of tumour is rare and the majority of the patients present with severe tumour mass-related symptoms leading them directly to neurosurgeons with often limited hormonal exploration. For this reason, only 14 of the 69 SCA cases in our pathology database were selected for our study, with the others being excluded because of a lack of hormonal data, and the absence of frozen samples available for molecular analysis. The clinical classification of SCA is also a challenge. Indeed, two of our patients initially classified as having a SCA due to the presence of clinical signs of tumour mass and the absence of typical symptoms of Cushing's disease were misclassified since hormonal data revealed a strong ACTH-dependent hypercortisolism despite the absence of clinical symptoms.

Four major studies have reported a total of 104 patients $(6,8,14,15)$; however, the majority of these were concerned to the histological characteristics of SCA, and few data were available on the clinical and hormonal status. Taking into account the data obtained from the literature and our results, we have been able to characterize SCA as a macroadenoma revealed by tumour mass-related symptoms with no clinical signs of hypercortisolism, normal plasma cortisol levels and elevated levels of ACTH, and ACTH or POMC peptide immunostaining. Patients with SCA are more likely to be men and are generally older than those with mCA (16). Baldeweg et al. (15) suggested that certain SCAs may have the potential for ACTH secretion leading to hypercortisolism at later stages of the disease. However, none of the patients included in the previous study had undergone preoperative hormonal evaluation, so the possibility that these patients harboured hormonal abnormalities despite presenting no clinical signs of
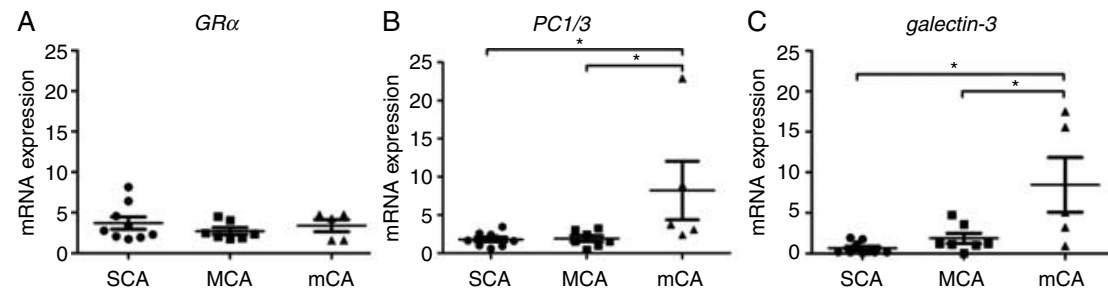

Figure 2 Relative mRNA expression of genes associated with SCA phenotype: $G R \alpha(\mathrm{A}), P C 1 / 3(\mathrm{~B})$ and galectin-3 (C) in the three groups of ACTH tumours. Gene expression in normal pituitary tissue was used as a standard and set to 1. RPL4 was used as an internal standard. Bars represent the median. ${ }^{\star} P<0.05$. 
Cushing's syndrome, as was the case for two of the cases in our cohort, cannot be excluded.

Our results also demonstrate a high degree of similarity between SCA and MCA groups in terms of i) sex ratio and age at diagnosis; ii) the high percentage of invasive tumours and high rate of recurrence (8, 17-20); iii) abnormalities of POMC processing demonstrated by the dissociation between cortisol and ACTH levels associated with low cortisol/ACTH ratio and weak expression of $\mathrm{PC1/3}$; iv) variability of the cytological differentiation, related to the ultrastructural classification into subtypes 1 and $2(3,4,6)$, and variability of the immunoreactivity of the three peptides of POMC sometimes observed (indeed, in some tumours, only $\beta$-endorphin or $\beta$-LPH immunostaining could be found) (21); v) the molecular variability of TPIT and POMC expression found in both groups but with a strong correlation in the expression levels of both genes; and vi) low galectin-3 expression at the mRNA level, previously described at the protein level by immunocytochemistry $(22,23)$. These characteristics confirm the similarities between MCA and SCA, and the differences with ACTH microadenomas with Cushing's disease which, in our opinion, should be considered separately from MCAs for all clinical, pathological and molecular analyses. Moreover, analysis of the ACTH and cortisol suppression during an i.v. dexamethasone test confirmed the results published previously (19, 24), demonstrating that MCAs are often associated with less glucocorticoid suppressibility than the more frequently occurring microadenomas. However, our results demonstrate that this resistance to glucocorticoid suppression could not be explained by the decrease in GR $\alpha$ expression.

The precise mechanisms behind the 'silence' in SCA are not yet clear. The dissociation between cortisol and ACTH levels, confirmed by the cortisol/ACTH ratio that is significantly lower in SCA, could provide an explanation for the 'silence' in SCA than in $\mathrm{mCA}$; however, it does not explain the difference between SCA and MCA, which have the same defect of POMC processing $(9,19,24,25)$. Although not statistically different in our study, ACTH levels tended to be higher in the MCA group than in the SCA group. We therefore propose that while less active $(19,24)$, the ACTH secreted by macroadenomas can induce hypercortisolism when a sufficient level of secretion is obtained by the size of the tumour or its secretory activity. This hypothesis could also explain the occurrence of hypercortisolism at later stages in patients with SCA (15).

One explanation for this POMC processing impairment is the defect in the expression of $P C 1 / 3$, a cleaving enzyme responsible for the post-translational processing of POMC into a mature ACTH (1-39) in corticotrophs. Immunohistochemical and RT-PCR studies have already demonstrated a decrease in $\mathrm{PC} 1 / 3$ expression in SCAs than in corticotroph adenomas $(26,27)$ or non-functioning pituitary adenomas (7, 26, 27). However, in these rare studies, few SCAs were analyzed, the hormonal data at presentation were sparse, and no distinction was made between micro- or macro-ACTH tumours. Our molecular analyses have demonstrated that the lower cortisol/ACTH ratio found in patients with SCA and MCA is associated with a lower expression of $\mathrm{PC} 1 / 3$.

Since there is no difference in the cortisol/ACTH ratio and $P C 1 / 3$ expression levels observed between SCA and MCA groups, other mechanisms must be responsible for the higher ACTH secretion among the MCA group than among the SCA group of patients. It has been suggested that SCA could be a less differentiated tumour (7) than MCA or mCA. To analyze the degree of differentiation of the SCA, we studied TPIT, a transcription factor which plays a key role in the corticotroph differentiation (28), and POMC expression observed in our tumours. A strong correlation was noted between TPIT and POMC expression in macro-ACTH tumours both with (MCA) or without (SCA) signs of hypercortisolism. Compared with those in the MCA or mCA groups, TPIT and POMC expression levels were lower in the SCA group with a histological corticotroph differentiation in five of the nine SCAs. Taken together, these data show that SCAs exhibit different levels of corticotroph differentiation with some being poorly differentiated ACTH tumours.

Other yet unidentified mechanisms associated with the silent phenotype of pituitary ACTH macroadenomas are likely (29). As published by Tateno et al. (7) our results confirm the absence of a role of GR $\alpha$ expression in this pathogenesis. Recently, Bilodeau et al. (30) demonstrated that Brg1 and HDAC2, proteins implicated in glucocorticoid feedback, may also participate towards the tumourigenesis of pituitary ACTH adenomas (31). However, no difference has been shown in this respect between SCAs and corticotroph adenomas with Cushing's disease (7).

Immunohistochemical studies have found high levels of expression of galectin-3 in corticotroph adenomas with Cushing's disease $(22,23)$, while SCAs exhibit very focal to null expression of galectin-3, suggesting a functional significance of the absence of galectin-3 expression in SCA. Although galectin-3 has been shown to have many possible functions, a role in hormone secretion has not been reported yet. With respect to our findings, the low levels of expression in SCA and MCA indicate that galectin-3 could be associated with cell differentiation rather than ACTH secretion. Initial studies in pituitary tumours (32) have shown that high expression levels of galectin-3 are associated with tumour aggressiveness, whereas the downregulation of galectin-3 can suppress tumourigenicity (33). However, the lower expression of galectin-3 in SCA (including one carcinoma) and MCA found in our study does not support a role for galectin-3 in pituitary tumour aggressiveness. 
In summary, SCAs are macro-ACTH tumours without clinical signs of hypercortisolism but with elevated ACTH levels and low cortisol/ACTH ratio, which exhibit histological, biochemical and molecular corticotroph differentiation. SCA and MCA show hormonal and molecular similarities differentiating them from mCA, and suggest common pathological pathways which differ from those involved in micro-ACTH tumours.

\section{Declaration of interest}

The authors declare that there is no conflict of interest that could be perceived as prejudicing the impartiality of the research reported.

\section{Funding}

Gerald Raverot is a recipient of the grant 'Jeune chercheur' from the Hospices Civils de Lyon, and this work was supported by a grant from the Ministère de la Santé (Programme Hospitalier de Recherche National no. 27-43).

\section{Acknowledgements}

We thank the Neurobiotec Bank, Angloscribe for help with the English translation, and A Reynaud for her excellent technical assistance.

\section{References}

1 Trouillas J, Barkan AL, Watson REJ, Lindell EP, Farrell WE \& Lloyd RV. ACTH pituitary adenoma. In World Health Organization Classification of Tumours. Pathology and Genetics of Tumours of Endocrine Organs, pp 26-29. Eds RA DeLellis, RV Lloyd, PU Heitz \& C Eng, Lyon: IARC Press, 2004.

2 Trouillas J. Pathology and pathogenesis of pituitary corticotroph adenoma. Neurochirurgie 200248 149-162.

3 Horvath E, Kovacs K, Killinger DW, Smyth HS, Platts ME \& Singer W. Silent corticotropic adenomas of the human pituitary gland: a histologic, immunocytologic, and ultrastructural study. American Journal of Pathology 198098 617-638.

4 Horvath E, Kovacs K, Smyth HS, Killinger DW, Scheithauer BW, Randall R, Laws ER Jr \& Singer W. A novel type of pituitary adenoma: morphological features and clinical correlations. Journal of Clinical Endocrinology and Metabolism $1988 \quad 66$ 1111-1118.

5 Tourniaire J. The so-called silent corticotropic pituitary adenoma. Presse Médicale 199120 197-198.

6 Scheithauer BW, Jaap AJ, Horvath E, Kovacs K, Lloyd RV, Meyer FB, Laws ER Jr \& Young WF Jr. Clinically silent corticotroph tumours of the pituitary gland. Neurosurgery 200047 723-729 discussion 729-730.

7 Tateno T, Izumiyama $\mathrm{H}$, Doi $\mathrm{M}$, Yoshimoto $\mathrm{T}$, Shichiri $\mathrm{M}$, Inoshita N, Oyama K, Yamada S \& Hirata Y. Differential gene expression in ACTH-secreting and non-functioning pituitary tumours. European Journal of Endocrinology 2007157 717-724.

8 Webb KM, Laurent JJ, Okonkwo DO, Lopes MB, Vance ML \& Laws ER Jr. Clinical characteristics of silent corticotrophic adenomas and creation of an internet-accessible database to facilitate their multi-institutional study. Neurosurgery 200353 1076-1084 discussion 1084-1075.

9 Reincke M, Allolio B, Saeger W, Kaulen D \& Winkelmann W. A pituitary adenoma secreting high molecular weight adrenocorticotropin without evidence of Cushing's disease. Journal of Clinical Endocrinology and Metabolism 198765 1296-1300.
10 Cottier J-P, Destrieux C, Brunereau L, Bertrand P, Moreau L, Jan M \& Herbreteau D. Cavernous sinus invasion by pituitary adenoma: MR imaging. Radiology 2000215 463-469.

11 Abou Samra AB, Dechaud H, Estour B, Chalendar D, Fevre-Montange M, Pugeat M \& Tourniaire J. Beta-lipotropin and cortisol responses to an intravenous infusion dexamethasone suppression test in Cushing's syndrome and obesity. Journal of Clinical Endocrinology and Metabolism $1985 \mathbf{6 1}$ $116-119$.

12 Brun J, Chamba G, Khalfallah Y, Girard P, Boissy I, Bastuji H, Sassolas G \& Claustrat B. Effect of modafinil on plasma melatonin, cortisol and growth hormone rhythms, rectal temperature and performance in healthy subjects during a $36 \mathrm{~h}$ sleep deprivation. Journal of Sleep Research 19987 105-114.

13 Murphy BE. Clinical evaluation of urinary cortisol determinations by competetive protein-binding radioassay. Journal of Clinical Endocrinology and Metabolism 196828 343-348.

14 Yamada S, Ohyama K, Taguchi M, Takeshita A, Morita K, Takano K \& Sano T. A study of the correlation between morphological findings and biological activities in clinically nonfunctioning pituitary adenomas. Neurosurgery 200761 580-584 discussion 584-585.

15 Baldeweg SE, Pollock JR, Powell M \& Ahlquist J. A spectrum of behaviour in silent corticotroph pituitary adenomas. British Journal of Neurosurgery 200519 38-42.

16 Korbonits M \& Carlsen E. Recent clinical and pathophysiological advances in non-functioning pituitary adenomas. Hormone Research 200971 (Suppl 2) 123-130.

17 Cho HY, Cho SW, Kim SW, Shin CS, Park KS \& Kim SY. Silent corticotroph adenomas have unique recurrence characteristics as compared with other non-functioning pituitary adenomas. Clinical Endocrinology 200972 648-653.

18 Blevins LS Jr, Christy JH, Khajavi M \& Tindall GT. Outcomes of therapy for Cushing's disease due to adrenocorticotropin-secreting pituitary macroadenomas. Journal of Clinical Endocrinology and Metabolism 199883 63-67.

19 Selvais P, Donckier J, Buysschaert M \& Maiter D. Cushing's disease: a comparison of pituitary corticotroph microadenomas and macroadenomas. European Journal of Endocrinology 1998138 153-159.

20 Woo YS, Isidori AM, Wat WZ, Kaltsas GA, Afshar F, Sabin I, Jenkins PJ, Monson JP, Besser GM \& Grossman AB. Clinical and biochemical characteristics of adrenocorticotropin-secreting macroadenomas. Journal of Clinical Endocrinology and Metabolism $2005904963-4969$.

21 Trouillas J, Girod C, Sassolas G, Vitte PA, Claustrat B, Perrin G, Lheritier M, Fischer C \& Dubois MP. A human beta-endorphin pituitary adenoma. Journal of Clinical Endocrinology and Metabolism $198458242-249$.

22 Jin L, Riss D, Ruebel K, Kajita S, Scheithauer BW, Horvath E, Kovacs K \& Lloyd RV. Galectin-3 expression in functioning and silent ACTH-producing adenomas. Endocrine Pathology 200516 $107-114$.

23 Thodou E, Argyrakos T \& Kontogeorgos G. Galectin-3 as a marker distinguishing functioning from silent corticotroph adenomas. Hormones 20076 227-232.

24 Katznelson L, Bogan JS, Trob JR, Schoenfeld DA, Hedley-Whyte ET, Hsu DW, Zervas NT, Swearingen B, Sleeper M \& Klibanski A. Biochemical assessment of Cushing's disease in patients with corticotroph macroadenomas. Journal of Clinical Endocrinology and Metabolism 199883 1619-1623.

25 Gibson S, Ray DW, Crosby SR, Dornan TL, Jennings AM, Bevan JS, Davis JR \& White A. Impaired processing of proopiomelanocortin in corticotroph macroadenomas. Journal of Clinical Endocrinology and Metabolism $1996 \mathbf{8 1} 497-502$.

26 Ohta S, Nishizawa S, Oki Y, Yokoyama T \& Namba H. Significance of absent prohormone convertase $1 / 3$ in inducing clinically silent corticotroph pituitary adenoma of subtype I - immunohistochemical study. Pituitary $20025221-223$. 
27 Tateno T, Izumiyama H, Doi M, Akashi T, Ohno K \& Hirata Y. Defective expression of prohormone convertase $1 / 3$ in silent corticotroph adenoma. Endocrine Journal 200754 777-782.

28 Vallette-Kasic S, Figarella-Branger D, Grino M, Pulichino AM, Dufour H, Grisoli F, Enjalbert A, Drouin J \& Brue T. Differential regulation of proopiomelanocortin and pituitary-restricted transcription factor (TPIT), a new marker of normal and adenomatous human corticotrophs. Journal of Clinical Endocrinology and Metabolism $2003 \mathbf{8 8}$ 3050-3056.

29 Grossman AB. The molecular biology of pituitary tumours: a personal perspective. Pituitary 200912 265-270.

30 Bilodeau S, Vallette-Kasic S, Gauthier Y, Figarella-Branger D, Brue T, Berthelet F, Lacroix A, Batista D, Stratakis C, Hanson J, Meij B \& Drouin J. Role of Brg1 and HDAC2 in GR trans-repression of the pituitary POMC gene and misexpression in Cushing disease. Genes and Development 200620 2871-2886.
31 Drouin J, Bilodeau S \& Vallette S. Of old and new diseases: genetics of pituitary ACTH excess (Cushing) and deficiency. Clinical Genetics 200772 175-182.

32 Riss D, Jin L, Qian X, Bayliss J, Scheithauer BW, Young WF Jr, Vidal S, Kovacs K, Raz A \& Lloyd RV. Differential expression of galectin-3 in pituitary tumours. Cancer Research 200363 2251-2255.

33 Honjo Y, Nangia-Makker P, Inohara H \& Raz A. Down-regulation of galectin-3 suppresses tumourigenicity of human breast carcinoma cells. Clinical Cancer Research 20017 661-668.

Received 27 March 2010

Accepted 12 April 2010 